\title{
EUROPEAN EARWIG AS A POTENTIAL BIOLOGICAL CONTROL AGENT OF APPLE LEAF-CURLING MIDGE
}

\author{
X.Z. HE, Q. WANG and J. XU \\ Institute of Natural Resources, Massey University, Palmerston North, \\ Private Bag 11222, New Zealand \\ Corresponding author: q.wang@massey.ac.nz
}

\begin{abstract}
The European earwig, Forficula auricularia L. is an important predator of aphids and scales in New Zealand apple orchards. To determine whether European earwig acted as a biological control agent of apple leaf-curling midge (ALCM), Dasineura mali Kieffer, their prey searching and feeding activity was investigated in the field and laboratory. In the field in January, earwigs started to leave their shelters at about 9:20 pm to search for ALCM larvae and returned to the shelters before 5:35 am, with a searching peak on apple shoots infested by ALCM larvae between 10:30 pm and 1:30 am. Significantly more ALCM infested shoots and leaves were bitten by earwigs on trees where shelters trapped earwigs than on those where shelters did not trap any earwigs. In the laboratory, earwigs mainly fed in the first 2 hours after light-off and each adult consumed an average of $67.70 \pm 3.18$ mature ALCM larvae during the scotophase $(8 \mathrm{~h})$. Heavier earwigs consumed significantly more ALCM larvae than light ones. Keywords: European earwig, Forficula auricularia, searching, feeding, Dasineura mali.
\end{abstract}

\section{INTRODUCTION}

Apple leaf-curling midge (ALCM), Dasineura mali Kieffer (Diptera: Cecidomyiidae), is a pest in most apple growing regions of New Zealand and its high incidence of infestations in many commercial orchards has raised quarantine problems in the apple industry (Smith \& Chapman 1995). ALCM has four or five generations per year in New Zealand apples (Shaw et al. 2005). Eggs are laid on young extending shoots, and larvae feed and grow on the leaves, making them rolled; mature larvae leave the curling-leaves and drop to the ground for pupation.

The European earwig, Forficula auricularia L. (Dermaptera: Forficulidae), is an important predator in pipfruit orchards. It has been reported to feed on eggs and active stages of a wide range of species of Lepidoptera, Coleoptera, Diptera, Homoptera, Hymenoptera and Collembola (Buxton 1974). European earwigs are efficient predators of key pests of economic importance in apple orchards such as apple aphids (Carroll et al. 1985), woolly apple aphids (Mueller et al. 1988; Nicholas et al. 2005) and scale insects (Karsemeijer 1973). In New Zealand, the potential economic importance of European earwigs in apple orchards has derived from the development of integrated fruit production (Walker et al. 2001; Suckling et al. 2003), which aims to maximise the efficiency of biological control programmes. More recently, Maher \& Logan (2007) investigated the effect of European earwigs on scale insect populations in kiwifruit orchards.

European earwigs are nocturnally active and shelter in dark crevices during the day (Lamb \& Wellington 1974; Burnip et al. 2002). This behaviour has been explored to develop trapping methods to monitor the seasonal population dynamics in orchards (Burnip et al. 2002; Suckling et al. 2006). However, the nocturnal activity of European earwigs is still poorly understood. Furthermore, no work has been done on the potential of this predator for the biological control of ALCM in New Zealand. In this paper, 
the nocturnal activity of prey searching and feeding activity of European earwig was investigated in the field and laboratory to determine whether this species could act as a biological control agent of ALCM.

\section{Field experiment}

\section{MATERIALS AND METHODS}

To investigate the earwig nocturnal patterns of prey searching activity, 30 shelters were established in an organic apple orchard, Massey University, Palmerston North, New Zealand, on 15 January 2008. Two rows of apple trees ('Braeburn', south-north orientation, 26 and 28 trees per rows, respectively) were used in the experiments. In each row, 15 shelters (one shelter per tree) were equally separated into three groups and placed in the both ends and centre of a row. Shelters consisted of corrugated cardboard pieces $(9 \mathrm{~cm}$ in length $\times 6.5 \mathrm{~cm}$ in width), which were rolled and individually inserted in a plastic container $(2.5 \mathrm{~cm}$ in diameter $\times 7 \mathrm{~cm}$ in height $)$ with one end opened. Shelters were individually attached horizontally to the trunks of trees $40 \mathrm{~cm}$ above the ground. A $9 \mathrm{~V}$ torch was used for observation in the field. Shelters were checked and the number of earwigs trapped per shelter recorded at 8:00 pm before observation on 17 to 18 January. To determine the prey searching activity of earwigs, 30 shoots infested by ALCM larvae per tree were examined hourly between $9: 30 \mathrm{pm}$ and 5:30 am from 17 to 19 January. The number of earwigs present on shoots was recorded for 30 trees with shelters. To determine the proportion of ALCM larvae infested shoots bitten by earwigs, ten trees with earwig(s) present in the shelters were randomly selected and 10 infested shoots per tree that were not bitten by earwigs were labelled on 19 January. Two trees with no earwigs in shelters were used as the control. The number of shoots and curling leaves bitten by earwigs were recorded daily during 20-24 January.

\section{Laboratory experiment}

To investigate the feeding behaviour of earwigs, 30 adults ( 15 males and 15 females) were collected from the field at 8:00 pm, 25 January 2008, brought back to the laboratory and individually weighed using an electric balance (Mettler Toledo, AG135, Switzerland) with a readability of $0.01 \mathrm{mg}$ to determine whether body weight had any effect on prey consumption. The feeding experiment started at 9:30 pm and terminated at 5:30 am to match the activity of earwigs in the field. Preliminary observation showed that a European earwig adult collected from the field consumed 38 mature ALCM larvae in 1 hour. Thus, each earwig was introduced to a Petri dish $(5.5 \mathrm{~cm}$ in diameter $\times 1.3 \mathrm{~cm}$ in height $)$ and provided with 40 mature ALCM larvae hourly under red light at $20^{\circ} \mathrm{C}$ and $65 \% \mathrm{RH}$. The number of ALCM larvae consumed per hour was recorded.

\section{Statistical analysis}

A goodness-of-fit test was used to test the distribution of data before analysis. Data for the total number of ALCM larvae consumed by an adult earwig and the accumulated proportion of infested shoots and leaves bitten by earwigs examined on the final day (i.e. 24 January) were not normally distributed even after transformation and were thus analysed using the nonparametric Kruskal-Wallis test (KWT) followed by Dunn's procedure for multiple comparisons. Data for the body weight of male and female earwigs were normally distributed and were thus analysed using ANOVA. Because the number of ALCM larvae consumed per hour and feeding patterns of earwigs during the scotophase were similar between male and female adults (Paired t-test: $t=0.58$, $\mathrm{P}>0.05$ ), those data were pooled and analysed using an analysis of non-linear regression (Fig. 3). The relationship between the number of ALCM larvae consumed and earwig body weight before feeding was analysed using an analysis of linear regression. 


\section{Field experiment}

\section{RESULTS}

European earwigs were trapped in 17 of 30 shelters with a total of 33 adults ( 18 males and 15 females) and one nymph. Earwigs started to leave the shelters at about 9:20 pm (sunset was at 8:45 pm) and no earwigs were found in the shelters when checked at 10:30 pm. The first earwig was found on shoots infested by ALCM larvae at 9:35 pm and 9:40 pm on 17 and 18 January, respectively. The searching activity was significantly higher $(\mathrm{P}<0.01)$ between 10:30 pm and 1:30 am (Fig. 1). All individuals returned to their shelters by 5:30 am (sunrise at 6:10 am). At 3:30 am, eight of $34(23.5 \%)$ individuals were found in the shelters when rain started at 2:30 am on 18 January and only 2 of 34 $(5.8 \%)$ returned to the shelters at the same time on 19 January, when there was no rain in the morning.

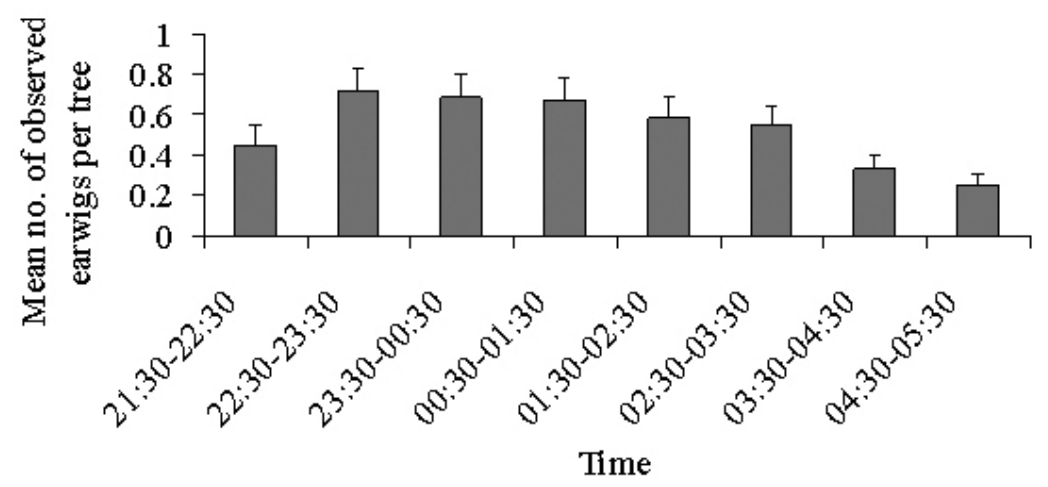

\section{FIGURE 1: Mean $( \pm \mathrm{SE})$ number of observed earwigs searching on infested shoots per tree based on two nights' observations in January.}

European earwigs usually bit the curling leaves infested with the late second or early third instar ALCM larvae. The accumulated proportion of shoots and curling leaves bitten by earwigs increased with time, and it was significantly higher on trees where earwigs were trapped in the shelters than for trees where no earwigs were trapped in shelters when examined on the final day (i.e. 24 January) (KWT: H=5.78 and 4.08 for shoots and leaves bitten by earwigs, respectively; P<0.05) (Fig. 2).

\section{Laboratory experiment}

In the laboratory, earwigs mainly fed in the first 2 hours after light-off, after which time feeding activity significantly decreased with time (non-linear regression: $\mathrm{P}<0.0001$ ) (Fig. 3). An adult earwig consumed an average of $67.70 \pm 3.18$ mature ALCM larvae during the scotophase $(8 \mathrm{~h})$. The earwig body weight before feeding $(61.35 \pm 3.77$ and $54.02 \pm 2.03 \mathrm{mg}$ for males and females, respectively) and total number of ALCM larvae consumed by an adult $(69.20 \pm 3.88$ and $66.20 \pm 5.15$ larvae consumed by males and females, respectively) were not significantly different between male and female adults (ANOVA: P>0 05 for body weight; KWT: $\mathrm{H}=0.21, \mathrm{P}>0.05$ for number of ALCM larvae consumed). The number of ALCM larvae consumed significantly increased with the increasing body weight of earwig adults before feeding (linear regression: $\mathrm{P}<0.0001$ ) (Fig. 4). 


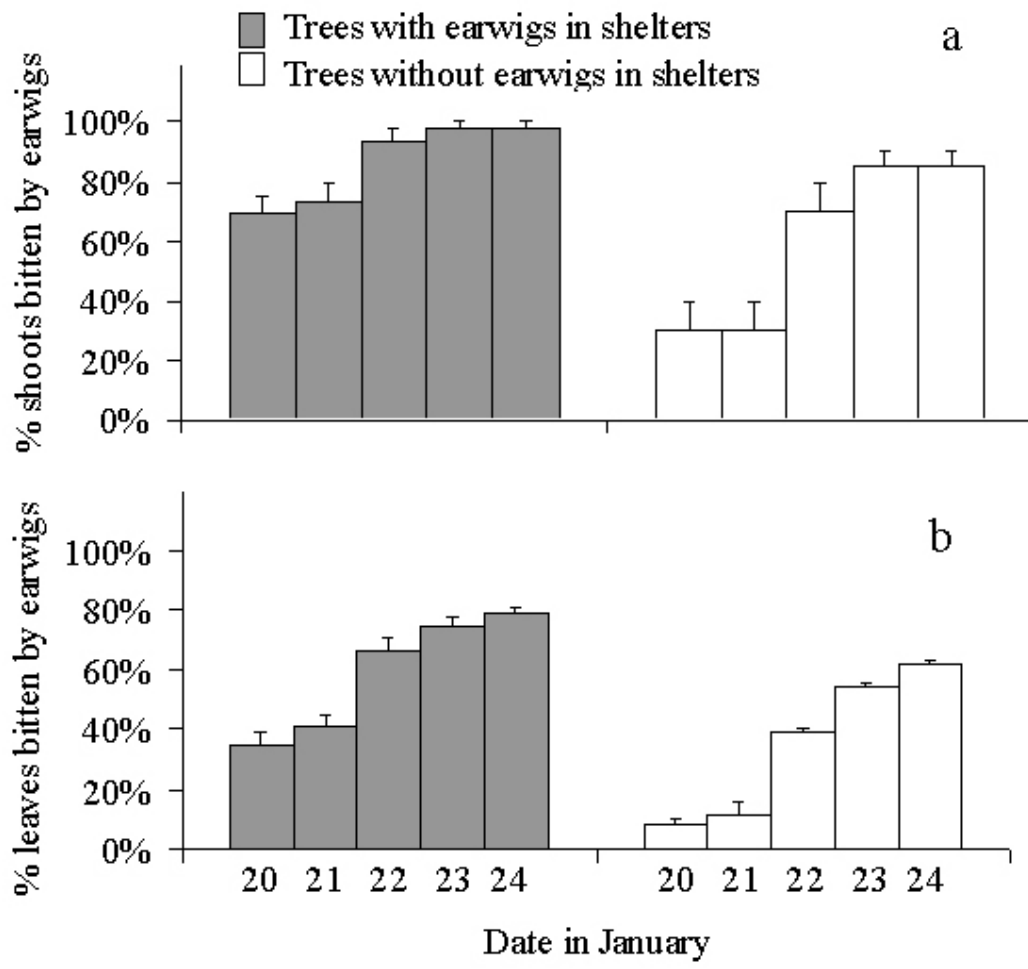

FIGURE 2: Proportion of (a) shoots and (b) leaves bitten by earwigs.

\section{DISCUSSION}

Animal periodicity is usually matched to daily and seasonal rhythms in the natural environment (Barnard 2004). The circadian activity of animals is usually linked to behavioural adaptations with consequences for reproduction, interspecific interactions or feeding strategies of prey and predators (Bell 1999). European earwig is a nocturnal predator, although food resources (e.g. aphids and ALCM) are available both at night and during the day in the orchards. Nocturnality of European earwig may be because in the orchards earwigs are the prey of birds (Flint 2002), and birds are usually diurnal in the orchards.

The field observations indicated that the searching activity of earwigs was regulated by the onset of sunrise and sunset. Most activity of prey searching and feeding by earwigs occurred during the early hours of scotophase and earwigs were relatively inactive during the later part of the scotophase. The activity pattern may be explained by the daily physiological hunger cycle as earwigs had starved during day time, which has been reported in other nocturnal predators (Walker et al. 1999). Earwigs returned to their shelters earlier if it rained, suggesting that rain may restrict earwig activity.

European earwig male and female adults consumed similar number of ALCM larvae, and this may be due to their similar body size. The larger earwigs of both sexes consumed more ALCM larvae. This may be due to their greater efficiency of prey capture and the need for more energy to sustain their relatively larger mass, as reported when they feed on the damson-hop aphids (Buxton \& Madge 1976). 


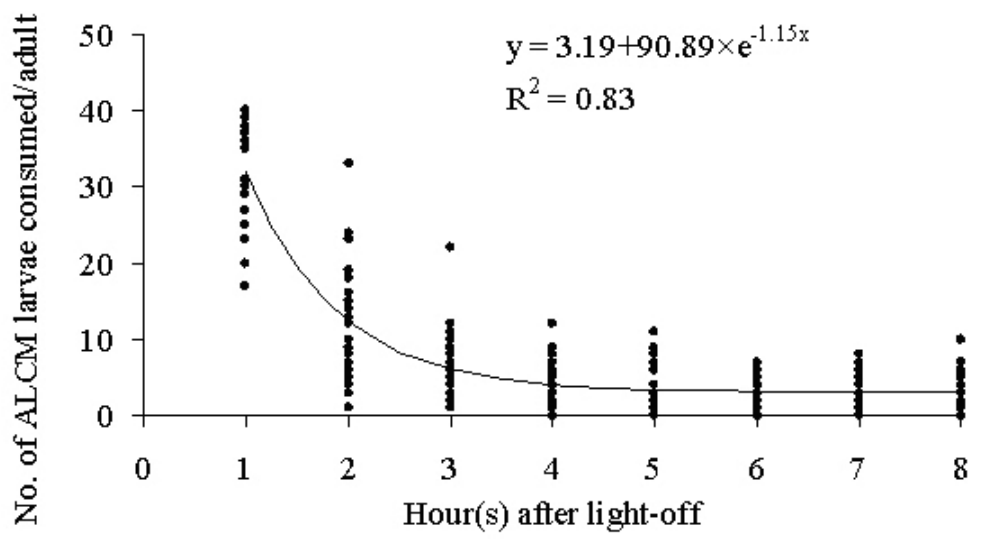

FIGURE 3: Number of mature ALCM larvae consumed by earwigs during the scotophase.

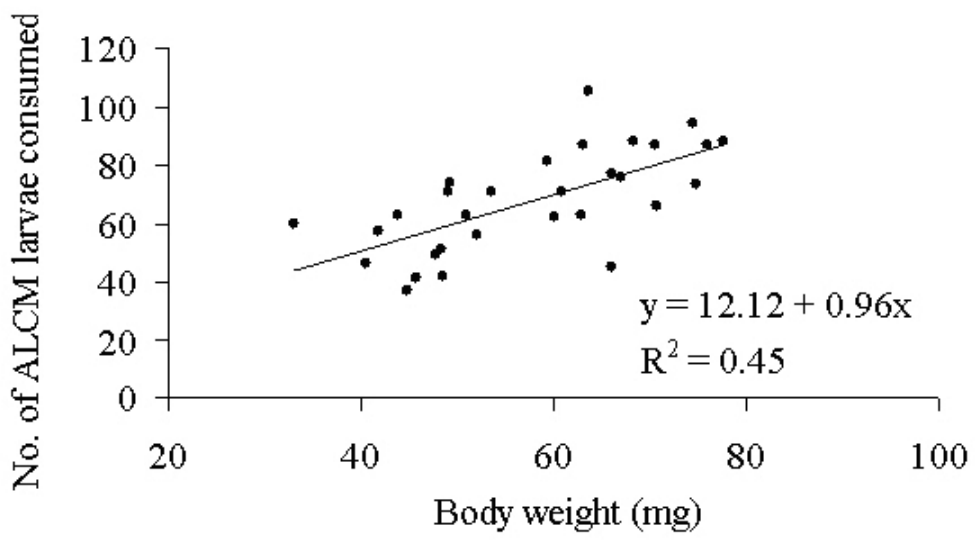

FIGURE 4: Relationship between the number of ALCM larvae consumed and body weight of earwigs before feeding.

In New Zealand, several predators were reported to attack ALCM, including the pirate bug Orius vicinus (Ribault), mirid bug Sejanus albisignata (Knight), whirligig mite Anystis baccarum (L.) and predatory mite Typhlodromus pyri Scheuten (ANON 2005). The present study is the first report of evidence for European earwig as a biological control agent of ALCM. The fact that the earwig can bite through the curled leaves and get direct access to ALCM larvae, and each adult can kill more than 60 ALCM larvae per night, suggests that this predator may be a highly efficient biological control agent for ALCM. Further investigation into this potential biological control agent for ALCM is warranted. For example, programmes like laboratory mass-rearing and field augmentation, conservation and trapping can be developed to biologically control ALCM populations using European earwigs. 


\section{ACKNOWLEDGEMENTS}

We thank Drs David Logan and Sue Zydenbos for their constructive comments on an earlier draft and the Plant Growth Unit, Massey University, Palmerston North, New Zealand, for allowing us to conduct the field experiments.

\section{REFERENCES}

ANON 2005. Apple leafcurling midge - Natural enemies. http://www.hortnet.co.nz/key/ keys /info/enemies/alm-enem.htm [accessed 12 December 2005].

Bell WJ 1999. Searching behavior patterns in insects. Annual Review of Entomology 35: 447-467.

Barnard CJ 2004. Animal behavior: mechanism, development, function and evolution. Pearson Education, Harlow, England. 726 pp.

Burnip GM, Daly JM, Hackett JK, Suckling DM 2002. European earwig phenology and effect of understorey management on population estimation. New Zealand Plant Protection 55: 390-395.

Buxton JH 1974. The biology of the European earwig, Forficula auricularia L. with reference to its predatory activities on the damson-hop aphid, Phorodon humuli (Shrank). PhD Thesis, University of London.

Buxton JH, Madge DS 1976. The evaluation of the European earwig (Forficula auricularia) as a predator of the damson-hop aphid (Phorodon humuli). I. Feeding experiments. Entomologia Experimentalis et Applicata 19: 109-114.

Carroll DP, Walker JTS, Hoyt SC 1985. European earwigs (Dermaptera: Forficulidae) fail to control apple aphids on bearing apple trees and woolly apple aphids (Homoptera: Aphididae) in apple rootstock stool beds. Journal of Economic Entomology 78: 972-974.

Flint ML 2002. Pest notes: earwigs. In: Ohlendorf B. ed. Integrated pest management for home gardeners. http://www.ipm.ucdavis.edu/PMG/PESTNOTES/pn74102. html [accessed 15 February 2008].

Karsemeijer MMD 1973. Observations on the enemies of the oyster shell scale, Lepidosaphes ulmi, on apple in the Netherlands. Netherlands Journal of Plant Pathology 79: 122-124.

Lamb RJ, Wellington WG 1974. Techniques for studying the behavior and ecology of the European earwig, Forficula auricularia (Demaptera: Forficulidae). Canadian Entomologist 106: 881-888.

Maher BJ, Logan DP 2007. European earwigs, Forficula auricularia, and predation of scale insects in organic and conventionally managed kiwifruit. New Zealand Plant Protection 60: 249-253.

Mueller TF, Blommers LHM, Mols PJM 1988. Earwig (Forficula auricularia) predation on the woolly apple aphid, Eriosoma lanigerum. Entomologia Experimentalis et Applicata 47: 145-152.

Nicholas AH, Spooner-Hart RN, Vickers RA 2005. Abundance and natural control of the woolly aphid Eriosoma lanigerum in an Australian apple orchard IPM programme. BioControl 50: 271-291.

Smith JT, Chapman RB 1995. A survey of apple leafcurling midge (Dasyneura mail) in the Nelson district. Proceedings of the 48th New Zealand Plant Protection Conference. Pp. 117-120.

Shaw PW, Wallis DR, Alspach PA, Sandanayaka WRM 2005. Phenology of apple leafcurling midge (Dasineura mali) in relation to parasitism by Platygaster demades. New Zealand Plant Protection 58: 306-310.

Suckling DM, Burnip GM, Hackett J, Daly JC 2006. Frass sampling and baiting indicate European earwig (Forficula auricularia) foraging in orchards. Journal of Applied Entomology 130: 263-267. 
Suckling DM, McKenna C, Walker JTS 2003. Integrated pest management in New Zealand horticulture. In: Maredia KM, Dakouo D, Mota-Sanchez D ed. Integrated pest management in the Global Arena. CABI Publishing, Wallingford. Pp. 385-396.

Walker JTS, Manktelow DWL, Wearing CH, Shaw PW, Lo PL, Suckling DM 2001. Development of integrated fruit production programmes in the New Zealand horticultural industry. IOBC/WPRS Bulletin 24: 51-56.

Walker SE, Marshall SD, Rypstra AL, Taylor DH 1999. The effects of hunger on locomotory behaviour in two species of wolf spider (Araneae, Lycosidae). Animal Behaviour 58: 515-520. 